\title{
Experimental Plans Method to Formulate a Resin
}

\section{Concrete}

\author{
Miloud Beddar ${ }^{1}$, Zinedine Boudaoud ${ }^{2}$, Mohamed Aziz Chikouche ${ }^{1}$ and Halima Saadia M'hammedi ${ }^{1}$ \\ 1. Faculty of Technology, civil engineering Department, M'sila University, M'sila 28000, Algeria \\ 2. Civil Engineering Department, Oum Elbouaghi University, OumElbouaghi 04000, Algeria
}

\begin{abstract}
This work is an experimental approach based on the method of experimental plans to determine a specific formulation of a resin concrete. In this study, an unsaturated polyester resin (thermosetting resin) was used with two types of mineral fillers (dune sand and crushed sand), and with the addition of a marble powder to ensure the continuity of the particle size mixing granular. The lack of the methods for developing this kind of composite materials, had led us to perform an initial experimental approach to define the experimental field, that is to say determine the mass proportions of the various compounds of mixture of our study. In the second approach, we have established and implemented fully experimental plans with three factors namely: Factor 1: sand, factor 2: resin, factor 3: marble powder. Test results being the density of polymer concrete and the mechanical resistances. Finally, multi-parameters regression allowed us to determine predictive mathematical models for the different responses of the study. Tests results showed that at three days we got a tensile strength of about $16 \mathrm{MPa}$ with a resin concrete density of $1.9 \mathrm{~g} / \mathrm{cm}^{3}$. This shows the advantages of this material.
\end{abstract}

Key words: Concrete, polyester resin, experimental plans method, mechanical resistance.

\section{Introduction}

Resin or polymer concrete is relatively new high performance material that has significantly progressed in the last 30 years. It is generally produced from a liquid resin mixed with coarse and fine inorganic aggregates such as gravel or crushed stone and sand. It is usually used in severe conditions in industrial and public buildings as well as transportation and hydraulic structures $[1,2]$.

Comparatively to the Portland cement concrete, resin concrete has high mechanical strength, good durability and in general greater resistance to the chemical products and corrosive agents [3]. It has also very low water absorption property and high freeze-throw stability.

The resins used to obtain a resin concrete are generally polymers based on four types of monomers or systems: methyl methacrylate, polyester

Corresponding anthor: Miloud Beddar, Dr., research fields: concrete technology, steel fibre and durability of concrete structures. E-mail: beddarm@yahoo.fr. prepolymer-styrene, epoxide prepolymer hardener and fiarfurolic alcohol $[4,5]$. The use of polymer resins in concrete as a binding material has shown that the strength and failure modes of the produced concrete are mainly influenced by curing method, temperature and strain rate.

The resin binders are usually two components systems: one containing the resin (base) and the other a hardener (in the case of epoxy resins) or an accelerator (in the case of polyester resins) that reacts with the resin to form the binding material $[6,7]$. The performance of resin concrete depends on the binder properties, type of filler and aggregates, curing temperature and components dosage.

The use of resin concrete has not limited on repair of structural elements, as it was, but it extended to be used with efficiency in precast components for buildings, bridges panels, hazardous waste containers, machine bases, and in various utility and transportation components $[8,9]$. 
The resin preferred in this study is an unsaturated isophatalic polyester resin because of its low cost. The concrete made from this kind of resin is hard, rigid, and has high mechanical strength, but there is the risk of cracking with thick block moulding due to the internal stresses related to shrinkage of resin [10].

The purpose of this study was to find the least amount of resin that be used to achieve acceptable strength and the cost effective in the same time. Following this step, the method of experimental plans to determine a specific formulation of a resin concrete was used.

\section{Materials and Specimens Preparation}

\subsection{Used Materials}

Sand: Two types of sand were used to prepare test specimens.

Dune sand: this is a clean, siliceous and fine sand of fraction 0/5 taken from BOUSAADA region. It was free of asphalt, dirt, and other organic materials. Its characteristics are regrouped in Table 1.

Quarry sand: This type of local well-graded sand is obtained by crushing of the limestone rock from the quarry of COSIDER situated in EL-EUCH region (B.B.A). Its physical proprieties were shown in Table 1.

\subsection{Resin}

The resin used in this study is unsaturated orthophthalic polyester, with blue color and a relative density of 1.25 . It is polymerized in cold by the addition of a catalyst. This unsaturated polyester orthophthalic was used as matrix. The initial styrene content is about $39 \%$ by weight, methyl ethyl ketone peroxide (about $1.5 \%$ by weight was added as catalyst, the accelerator is the cobalt octoate (environ $0.2 \%$ by weight) [11].

\subsection{Marble Powder}

It is a very fine powder, one of its main constituent is $\mathrm{CaCO}_{3}$. Its granularity is varied between 30 to $40 \mu \mathrm{m}$ and its relative density equals to $2.71 \mathrm{~g} / \mathrm{cm}^{3}$. The chemical composition of the powder is given in Table 2 .

\subsection{Specimens Preparation.}

Preliminary phase: first, due to the lack of methods to formulate a resin concrete, the objective of the first phase was the research for a resin concrete which should be homogenous easy to be implemented. For this, the amount of sand was fixed while the two other parameters namely the resin and marble powder are variable.

Resin content: The content of the resin used in this study varies between $15 \%$ and $30 \%$ by weight in comparison with the other constituents. The ration in weight between the marble powder $\left(\mathrm{P}_{\mathrm{m}}\right)$, and the unsaturated polyester resin $\left(\mathrm{P}_{\mathrm{r}}\right)$ varies between 0 and $50 \%$. The different proportion of the materials used is regrouped in Table 3 according to the fraction below:

$$
\left\{\begin{array}{l}
\frac{\mathrm{P}}{\mathrm{P}_{\mathrm{S}}+\mathrm{P}_{\mathrm{R}}+\mathrm{P}_{\mathrm{M}}}=15-20-25-30 \% \\
\frac{\mathrm{P}_{\mathrm{M}}}{\mathrm{P}}=0-25-50 \%
\end{array}\right.
$$

\section{Presentation of the Obtained Results}

Mixes based on the materials mentioned above were mixed according to the Table 3 and cast in $40 \times 40 \times 160$ $\mathrm{mm}$ prisms [12]. They were prepared by mixing the polyester resin and hardener and, then adding the considered charges (dune and quarry sand, polyester resin and marble powder). These preliminary tests have

Table 1 Hysical properties of dune and quarry sand used in this study.

\begin{tabular}{lll}
\hline Characteristics & Dune sand & Quarry sand \\
\hline Density & 2.60 & 2.48 \\
Bulk density in loose state & 1.703 & 1.640 \\
Bulk density in compact state & 1.603 & 1.50 \\
Porosity in compact state & $32.61 \%$ & $34.4 \%$ \\
Porosity in loose state & $38.35 \%$ & $40 \%$ \\
Compactness & 64.8 & 70.55 \\
Sand equivalent visual/piston & $80.8 / 78.7$ & $/ / /$ \\
\hline
\end{tabular}


Table 2 Chemical composition of marble powder.

\begin{tabular}{llllllll}
\hline $\mathrm{SiO}_{2}$ & $\mathrm{CaO}$ & $\mathrm{Al}_{2} \mathrm{O}_{3}$ & $\mathrm{Fe}_{2} \mathrm{O}_{3}$ & $\mathrm{MgO}$ & $\mathrm{SO}_{3}$ & $\mathrm{~K}_{2} \mathrm{O}$ & $\mathrm{Na}_{2} \mathrm{O}$ \\
\hline 1.47 & 55.3 & 0.35 & 0.14 & 0.01 & 0.01 & 0.04 & 0.12 \\
\hline
\end{tabular}

Table 3 Different proportions of used materials.

\begin{tabular}{lll}
\hline Ps (sand) [gr] & Pr (resin) [gr] & Pm (marble) [gr] \\
\hline \multirow{3}{*}{500} & 88.23 & 0 \\
& 125 & 0 \\
& 166.67 & 0 \\
& 214.28 & 0 \\
\hline \multirow{3}{*}{500} & 92.30 & 14.28 \\
& 133.33 & 33.33 \\
& 181.81 & 45.45 \\
& 240 & 60 \\
\hline \multirow{3}{*}{500} & 96.77 & 48.38 \\
& 142.85 & 71.43 \\
& 200 & 100 \\
\hline
\end{tabular}

revealed us some remarks with respect to the density, compressive and tensile strength.

\subsection{Bulk Density}

As shown in Fig. 1, the bulk density of the tested specimens decreases with increasing the content of resin by weight. This diminution is due to the main characteristics of the unsaturated polyester resin which is the lightness. The bulk density is varied between 1.79 and $2.01 \mathrm{~g} / \mathrm{cm}^{3}$.

\subsection{Tensile Strength}

Specimens were tested in indirect tension after 28 days of curing at room temperature. The results obtained have been reported in Fig. 2.

Test results show that at $15 \%$ by weight of the resin which means the lowest content of this study, the tensile strength is very low. This can be explained by the fact that resin has not wrapped all the grains of sand to create a union between the grains so that they are detached from each other. However, at $20 \%$ by weight the resin, curve is already at the maximum which means a good cohesion between the different constituents of the material.

\subsection{Compressive Strength}

The results obtained after testing all the specimens under compressive load are shown in Fig. 3. The increase in the amount of resin increases the compressive strength as it is shown in the Fig. 3. This can be explained by the fact that the used resin provides to the mixture its characteristic strength. A strength of

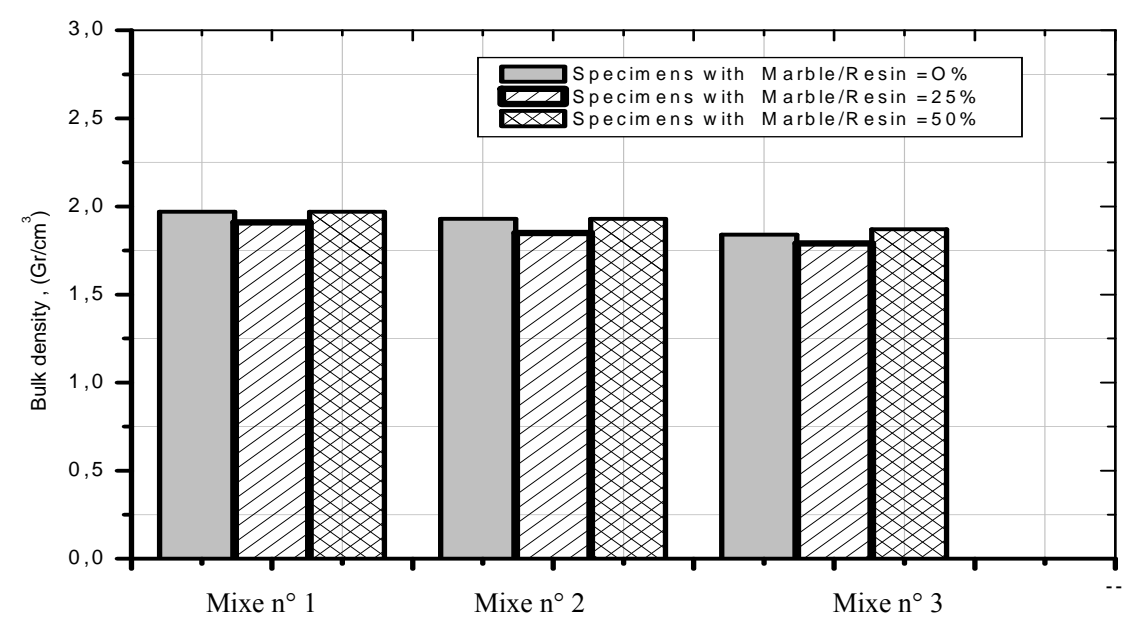

Fig. 1 Variation of bulk density in function of $\frac{\text { Marble }}{\text { Resin }}$. 


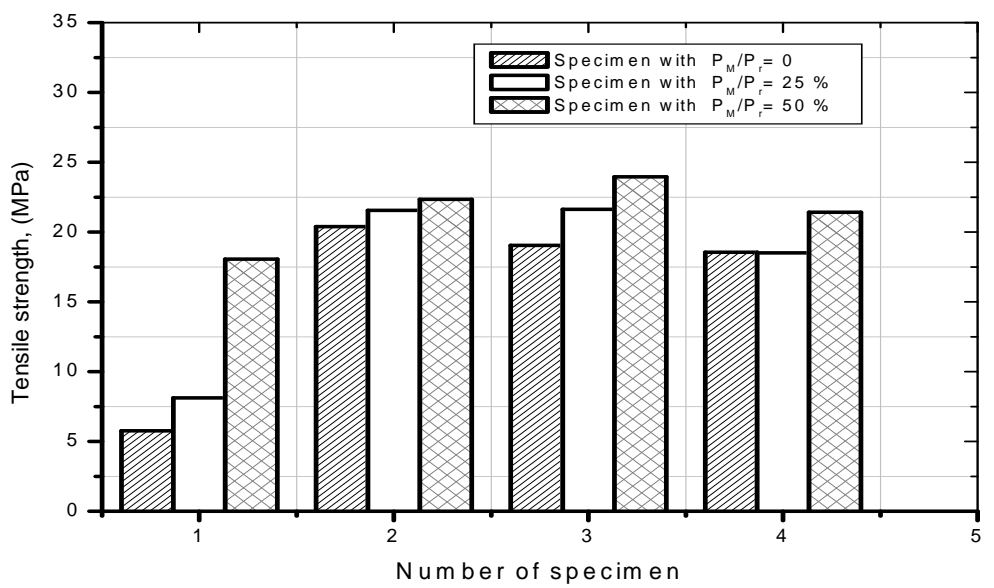

Fig. 2 Variation of $\mathbf{R}_{\mathbf{t} 28}$ in function of $\frac{\text { Marble }}{\text { Resin }}$.

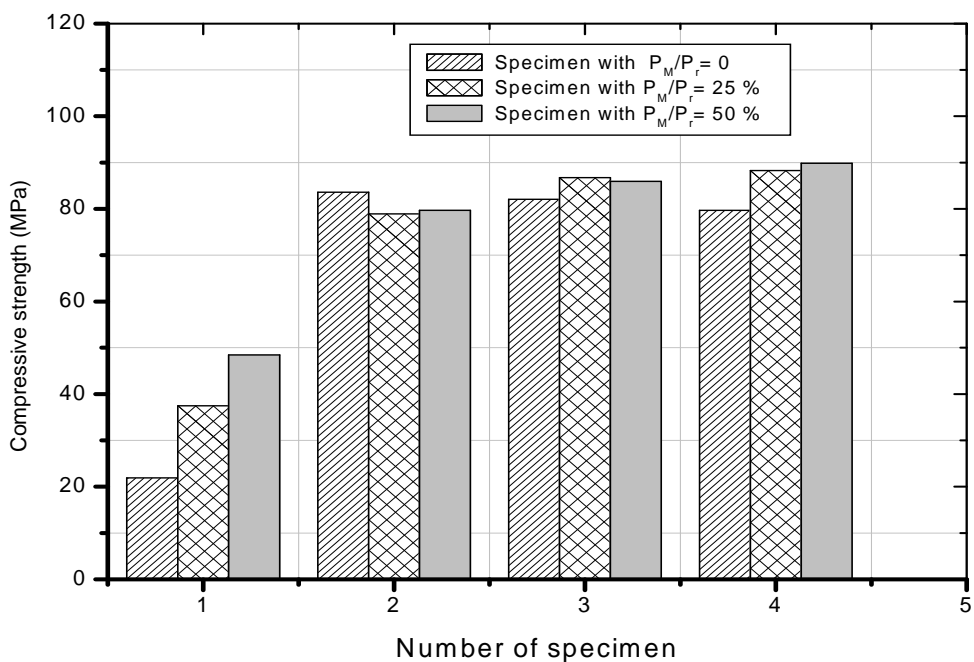

Fig. 3 Variation of $\mathbf{R}_{\mathbf{c 2 8}}$ in function to $\frac{\text { Marble }}{\text { Resin }}$.

$90 \mathrm{MPa}$ can be seen in these results with an amount of $30 \%$ by weight of resin.

\section{Experimental Plans}

We have opted for the technology of the experimental plans because, in comparison with a classical approach, we shall have a good quality of results, and a predictive capacity of trial results due to the mathematical modelling which allows by this method. This modeling allows the calculation of the value and the sign of the influential factors which maximize or minimize the system response [13-15]. This method also allows:

The knowledge of the parameters effects, and the deduction of influential parameters;

The possibility of assessing the correlations effects between parameters; 
If experimental field is known enough, this technology can allow the reduction of some tests in this study.

\subsection{The Three Factors of Study}

Having performed preliminary study, we deducted the levels of the different factors of this study. The three factors are at two levels (Tables 4 and 5), which give us for a full factorial plan, eight tries to be accomplished.

This kind of plan allows the determination of all factors effect of this study and their respective significance in the response. It allows the writing of a complete mathematical model as follows:

$$
\begin{array}{r}
\mathrm{Y}=\mathrm{A}_{0}+\mathrm{A}_{1} \mathbf{S}+\mathrm{A}_{2} \mathbf{R}+\mathrm{A}_{3} \mathbf{M}+\mathrm{A}_{12} \mathbf{S} . \mathbf{R}+\mathrm{A}_{23} \mathbf{R} . \\
\mathbf{M}+\mathrm{A}_{13} \mathbf{S} . \mathbf{M}+\mathrm{A}_{123} \text { S.R.M }
\end{array}
$$

\section{Matrices and Responses of Different Factors}

\subsection{Bulk Density}

The different measurements of the bulk density of the plan and the effects of the different factors are given in Table 6.

Range of bulk density which is $(1.79,2.14)$ enables us to say that the made concrete belongs to the lightweight category of building materials. With the reading of the results of the multi-parametric regression, it appears clearly that:

The quarry sand, the presence of marble powder and a strong percentage of resin increase the density;

The interaction between the resin (up to 30\%) and marble powder is very significant.

Table 4 Different factors and levels of the experimental plans method.

\begin{tabular}{llllll}
\hline & Sand (S) & \multicolumn{2}{c}{ Unsaturated polyester resin (R) } & \multicolumn{2}{c}{ Marble powder (M) } \\
\hline Level (-1) & Level (+1) & Level $(-1)$ & Level $(+1)$ & Level $(-1)$ & Level $(+1)$ \\
Dune sand & Quarry sand & $20 \%$ & $30 \%$ & $0 \%$ & $30 \%$ \\
\hline
\end{tabular}

Table 5 Test matrix.

\begin{tabular}{llll}
\hline $\mathrm{N}^{\circ}$ of experience & $\mathrm{S}$ & $\mathrm{R}$ & $\mathrm{M}$ \\
\hline 1 & -1 & -1 & -1 \\
2 & +1 & -1 & -1 \\
3 & -1 & +1 & -1 \\
4 & +1 & +1 & -1 \\
5 & -1 & -1 & +1 \\
6 & +1 & -1 & +1 \\
7 & -1 & +1 & +1 \\
8 & +1 & +1 & +1 \\
\hline
\end{tabular}

Table 6 The matrix of the effects and the measurements of the bulk density (G/CM$\left.{ }^{3}\right)$.

\begin{tabular}{llllllllll}
\hline Test & Average & $\mathrm{M}$ & $\mathrm{R}$ & $\mathrm{S}$ & $\mathrm{R} . \mathrm{M}$ & $\mathrm{S} . \mathrm{R}$ & $\mathrm{S} . \mathrm{M}$ & R.S. M & B.D \\
\hline 1 & 1 & -1 & -1 & -1 & 1 & 1 & 1 & -1 & 1.87 \\
2 & 1 & -1 & -1 & 1 & 1 & -1 & -1 & 1 & 1.79 \\
3 & 1 & -1 & 1 & -1 & -1 & -1 & 1 & 1 & 1.95 \\
4 & 1 & -1 & 1 & 1 & -1 & 1 & -1 & -1 & 2.14 \\
5 & 1 & 1 & -1 & -1 & -1 & 1 & -1 & 1 & 1.83 \\
6 & 1 & 1 & -1 & 1 & -1 & -1 & 1 & -1 & 1.82 \\
7 & 1 & 1 & 1 & -1 & 1 & -1 & -1 & -1 & 1.87 \\
8 & 1 & 1 & 1 & 1 & 1 & 1 & 1 & 1 & 1.91 \\
\hline \multirow{2}{*}{ Effect } & A0 & A3 & A2 & A1 & A23 & A12 & A13 & A123 & \multirow{2}{*}{1.93} \\
\hline
\end{tabular}




\subsection{Tensile Strength}

It is noted that the resin and the marble powder play a major role. To obtain a high tensile strength, the mixture of the dune sand with marble powder (continuous granularity) and $20 \%$ by weight of resin will give this result. Table 7 will give the matrix of tensile strength effects of different tests.

\subsection{Compressive Strength}

All the factors effects are significant in the compressive strength model and even certain interactions. It is noticed also that the factors have the same effects on the compressive strength as on the tensile strength. Table 8 will give the matrix of the compressive strength effects of different tests.

\section{Effect of Factors Variation}

\subsection{Effect of Factors Variation on Bulk Density}

It is observed that for all the test specimens, as soon as there is an increase in the percentages by weight of the resin, the test specimen becomes lighter as it is clearly shown by the experimental plan, and the interval of this density which ranges between 1.79 and 2.14 enables us to say that the made concrete belongs to the light category. All the results are reported in Table 9 and Fig. 4.

\subsection{Effect of Factors Variation on the Tensile Strength}

It is noticed that the quarry sand offers a poor strength while the dune sand of makes it higher. The

Table 7 Matrix of tensile strength effects of different tests.

\begin{tabular}{llllllllll}
\hline Test & Average & $\mathrm{M}$ & $\mathrm{R}$ & $\mathrm{S}$ & $\mathrm{R} . \mathrm{M}$ & $\mathrm{S} . \mathrm{R}$ & $\mathrm{S} . \mathrm{M}$ & $\mathrm{R} . \mathrm{S} . \mathrm{M}$ & $\mathrm{f}_{\mathrm{t}}$ \\
\hline 1 & 1 & -1 & -1 & -1 & 1 & 1 & 1 & -1 & 11.93 \\
2 & 1 & -1 & -1 & 1 & 1 & -1 & -1 & 1 & 21.43 \\
3 & 1 & -1 & 1 & -1 & -1 & -1 & 1 & 1 & 16.94 \\
4 & 1 & -1 & 1 & 1 & -1 & 1 & -1 & -1 & 17.15 \\
5 & 1 & 1 & -1 & -1 & -1 & 1 & -1 & 1 & 10.48 \\
6 & 1 & 1 & -1 & 1 & -1 & -1 & 1 & -1 & 16.73 \\
7 & 1 & 1 & 1 & -1 & 1 & -1 & -1 & -1 & 16.52 \\
8 & 1 & 1 & 1 & 1 & 1 & 1 & 1 & 1 & 16.75 \\
\hline \multirow{2}{*}{ Effect } & A0 & A3 & A2 & A1 & A23 & A12 & A13 & A123 & \multirow{2}{*}{17.69} \\
& 15.99 & 2.02 & 0.85 & -0.87 & -1.91 & 0.45 & -0.40 & 0.41 & \\
\hline
\end{tabular}

Table 8 Matrix of the compressive strength effects of different tests.

\begin{tabular}{llllllllll}
\hline Test & Average & $\mathrm{M}$ & $\mathrm{R}$ & $\mathrm{S}$ & $\mathrm{R} . \mathrm{M}$ & $\mathrm{S} . \mathrm{R}$ & $\mathrm{S} . \mathrm{M}$ & $\mathrm{R} . \mathrm{S} . \mathrm{M}$ & $\mathrm{f}_{\mathrm{c}}$ \\
\hline 1 & 1 & -1 & -1 & -1 & 1 & 1 & 1 & -1 & 46.88 \\
2 & 1 & -1 & -1 & 1 & 1 & -1 & -1 & 1 & 62.03 \\
3 & 1 & -1 & 1 & -1 & -1 & -1 & 1 & 1 & 61.72 \\
4 & 1 & -1 & 1 & 1 & -1 & 1 & -1 & -1 & 71.09 \\
5 & 1 & 1 & -1 & -1 & -1 & 1 & -1 & 1 & 39.06 \\
6 & 1 & 1 & -1 & 1 & -1 & -1 & 1 & -1 & 59.69 \\
7 & 1 & 1 & 1 & -1 & 1 & -1 & -1 & -1 & 57.03 \\
8 & 1 & 1 & 1 & 1 & 1 & 1 & 1 & 1 & 55.47 \\
\hline \multirow{2}{*}{ Effect } & A0 & A3 & A2 & A1 & A23 & A12 & A13 & A123 & \multirow{2}{*}{58.59} \\
& 56.62 & 5.45 & 4.71 & -3.81 & -3.50 & -1.72 & -0.68 & -2.05 & \\
\hline
\end{tabular}


Table 9 Response of different factors on the bulk density.

\begin{tabular}{lll}
\hline & -1 & 1.915 \\
Sand (Factor 1) & 0 & 1.8975 \\
& 1 & 1.88 \\
\hline \multirow{2}{*}{ Resin (Factor 2) } & -1 & 1.9675 \\
& 0 & 1.8975 \\
& 1 & 1.8275 \\
\hline & -1 & 1.8575 \\
Marble powder (Factor 3) & 0 & 1.8975 \\
& 1 & 1.9375 \\
\hline
\end{tabular}

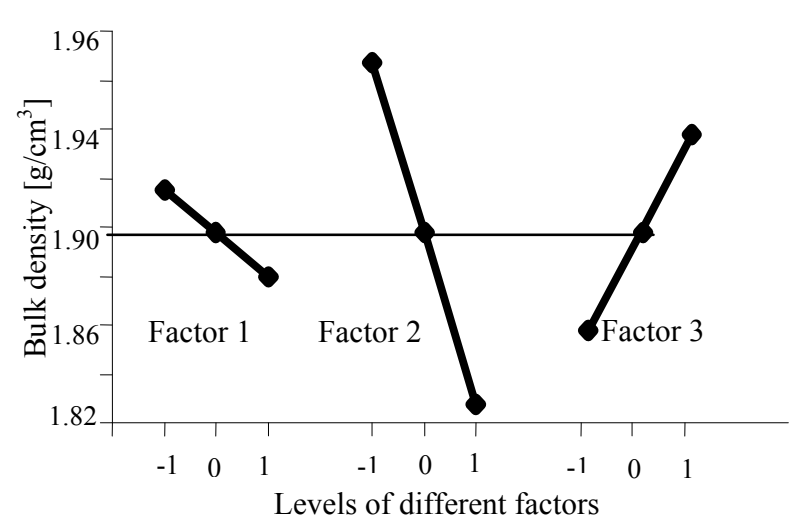

Fig. 4 Response of different factors on the bulkdensity.

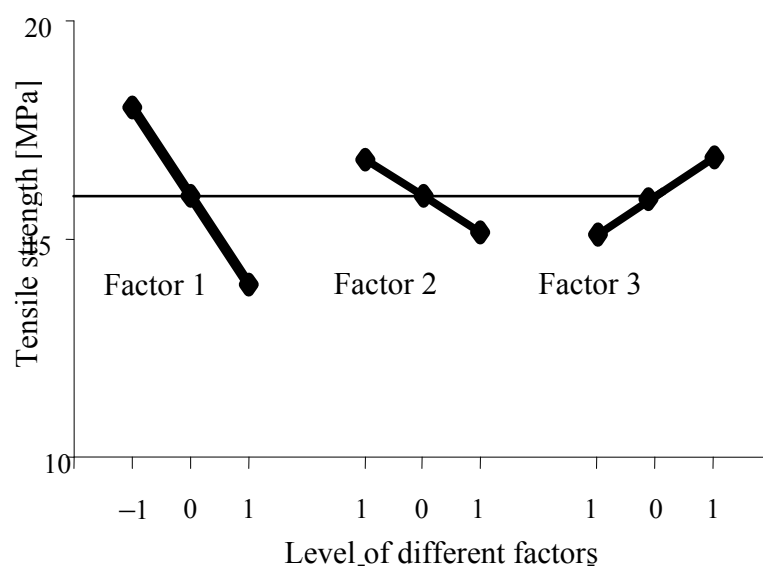

Fig. 5 Response of different factor on the tensile strength.

resin must be estimated with precision because a great quantity of resin can disrupt the strength and make it lower, while a continuous granularity gives an output higher. This high strength can be offered by the marble powder. Table 9 shows the response of different factors for tensile strength.
6.3 Effect of Factors Variation on the compressive Strength

Compressive strength results are reported in Table 10 in which, it is clearly shown that dune sand gives a better performance than quarry sand, and the resin is a determinant factor to obtain a high compressive strength. Table 1 shows the effect of level of different factors on compressive strength. All results are shown in Table 11 and illustrated in Fig. 6.

Table 10 Responses of different factors for tensile strength.

\begin{tabular}{lll}
\hline & -1 & 18.018 \\
Sand (Factor 1) & 0 & 15.9939 \\
& 1 & 13.9698 \\
\hline \multirow{2}{*}{ Resin (Factor 2) } & -1 & 16.8422 \\
& 0 & 15.9939 \\
& 1 & 15.1457 \\
\hline \multirow{2}{*}{ Marble powder (Factor3) } & -1 & 15.1223 \\
& 0 & 15.9939 \\
\hline
\end{tabular}

Table 11 Effect of level of different factors on compressive strength.

\begin{tabular}{lll}
\hline & -1 & 62.07 \\
Sand Factor 1 & 0 & 56.62125 \\
& 1 & 51.1725 \\
\hline \multirow{2}{*}{ Resin Factor 2 } & -1 & 61.3275 \\
& 0 & 56.62125 \\
& 1 & 51.915 \\
\hline \multirow{2}{*}{ Marble powder Factor 3 } & -1 & 52.8125 \\
& 0 & 56.62125 \\
& 1 & 60.43 \\
\hline
\end{tabular}

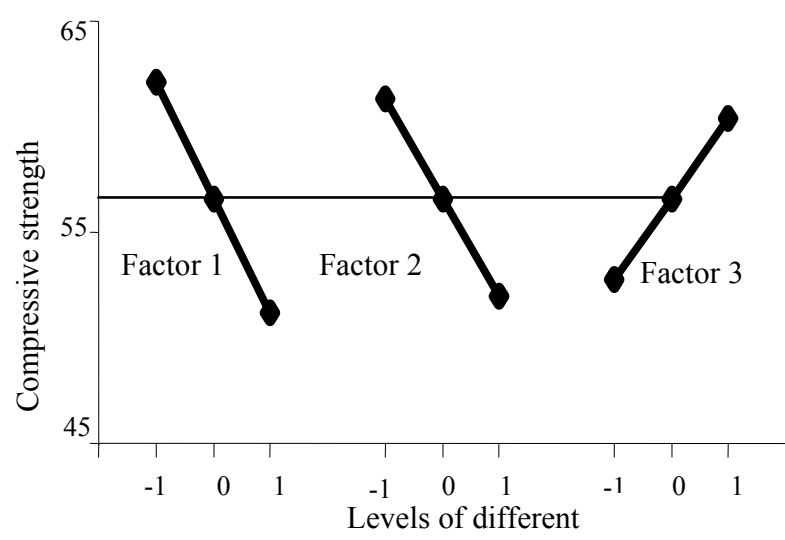

Fig. 6 Response of different factors on compressive strength. 


\section{Conclusions}

This experimental study concerning the unsaturated resin concrete has as principal objective which is to formulate a resin concrete by using the experimental plans as a method to get the optimal proportions of different constituents. Experiments were planned and executed according to the factorial design technique using three variables at two levels.

The results obtained showed that the experimental plans method is a feasible method to formulate this special concrete.

This study shown also that the resin concrete using an unsaturated polyester resin and local materials is a very feasible material for building applications and public works. Even its use is very specific and limited to repair works, the addition of dune sans and marble powder improves the mechanical properties and reduced the cost of the composite.

In general, on the basis on the test results, the following conclusions can be made:

(1) This kind of concrete is lightweight, its bulk density is around $1.89 \mathrm{~g} / \mathrm{cm}^{3}$;

(2) The tensile strength is tripled compared to the strength of traditional concrete even with aggregates of higher dimension;

(3)The compressive strength reaches a more substantial numbers of high performance concrete;

(4)A mixture of sand dune and a content of $20 \%$ by weight of the resin provide the best experimental responses;

(5)The continuity of the mixture in this type of concrete is preferred to get high performance.

\section{References}

[1] Y. Ohama, Concrete-polymer Composite: The past, present and future, Key Engineering Materials,
Scientific.net 466 (2011) 1-14.

[2] L. K. Aggarwal, Properties of polymer modified mortars using epoxy and acrylic emulsions, Construction and Building Materials 21 (2) (2007) 379-383.

[3] W. S. Wahby, Fifty years history of polymer in concrete in review, ACI International (2003) 13-14.

[4] W. J. Byung, S. K. Park and D. K. Kim, Mechanical properties of nano-MMT reinforced polymer composite and polymer concrete, Construction and Building Materials 22 (2002) 14-20.

[5] N. Ahn, Effects of diacrylate monomers on the bond strength of polymer concrete to wet substrates, Journal of Applied Polymer Science 90 (2003) 991-1000.

[6] A. Blaga and J. J. Beaudoin, Polymer Modified Concrete, Division of Building Research, National Research Council Canada, Canadian Building Digest, Ottawa, 1985, p. 241.

[7] K. S. Rebeiz, Precast of polymer concrete using unsaturated polyester resin based on recycled PET waste, Construction and Building Materials 10 (3) (1996) 215-250.

[8] M. C. S. Ribeiro, C. M. S. Tavares, M. Figueiredo and A. J. M. Ferreira, Bending characteristics of resin concretes, Materials Research 6 (2) (2003) 247-254.

[9] H. Abdelfattah and M. Elhawary, Flexural behavior of polymer concrete, Construction and Building Materials 13 (1999) 253-262.

[10] M. Rokbi, Behaviour in rupture and mechanical characteristics of polyester-glass fibre composites, M.Sc thesis, M'sila University, 2001.

[11] J. Baron and J. P. Ollivier, Concretes: Data Bases of Mix Design (3rd ed.), Eyrolls edition, Paris, 1996, pp. 410-470.

[12] RILEM PC2, Technical Comittee TC-113, Method of making polymer concrete and mortar specimens, in: Symposium on Properties and Test Methods for Concrete -Polymer Composites, Ostende, 1995, pp. 129-132.

[13] H. H. G. Harris and G. M. Sabnis, Structural Modeling and Experimental Techniques, CRC Press, 1999.

[14] R. A. Bailey, Design of Comparative Experiments, Pre-publication chapters are available on-line, Cambridge University Press, 2008.

[15] G. E. Box, W. G. Hunter, J. S. Hunter and W. G. Hunter, Statistics for Experimenters: Design, Innovation, and Discovery (2nd ed.), Wiley, 2005. 